\title{
Elas Digitais: protagonismo feminino para falar de cursos e carreiras na área de Computação
}

\author{
Caroline Reis Vieira Santos Rauta ${ }^{1}$, Daniela Sbizera Justo ${ }^{1}$, Rayana Prata Neves ${ }^{1}$, \\ Djhesica Moreira Cortez ${ }^{1}$, Amanda de Oliveira Casagrande ${ }^{1}$ \\ ${ }^{1}$ Departamento de Ensino, Pesquisa e Extensão - Instituto Federal de Santa Catarina - \\ Câmpus Gaspar (IFSC) \\ Rua Adriano Kormann, 510, - Bela Vista - Gaspar - SC - Brasil
}

\{caroline.reis, daniela.sbizera\}@ifsc.edu.br, \{rayana.p, djhesica.m amanda.c06\} ealuno.ifsc.edu.br,

\begin{abstract}
This paper presents an extension project that aimed developing material created by and for women to disseminate information regarding Computing careers. After a call through an e-mail list for female participants for an interview and based on the responses received by those participants, a research was carried out on the courses of Computer Science (both Bachelor and Licentiate degrees) Information Systems and Computer Engineering. As a result, four podcast episodes and two folders were produced with information about the courses mentioned above. This material was hosted by the project's web page to be freely reproduced and distributed in event involving women.
\end{abstract}

Resumo. Este trabalho apresenta um projeto de extensão cujo objetivo foi criar materiais com protagonismo feminino para divulgar carreiras na área da Computação. Foi realizada uma chamada via e-mail para entrevistas para as participantes do Elas Digitais e, a partir da adesão das profissionais de diferentes graduações, foi realizada pesquisa sobre os cursos de Licenciatura em Computação, Sistemas de Informação, Ciência da Computação e Engenharia de Computação. Como resultado, produziram-se quatro episódios de podcast e dois fôlderes com informações sobre os cursos supracitados. Esse material foi disponibilizado pela página do projeto para reprodução gratuita e distribuição em eventos que envolvam mulheres.

\section{Introdução}

Acredita-se que, por estarmos na era da informação rápida, todos, todas e todes se apropriem dela, mas como se vê no estudo de [Macedo et al. 2018], ainda há falta de acesso à informação. Embora haja materiais disponíveis sobre cursos da área da Computação em variadas fontes, como os próprios "Referenciais de Formação para os Cursos de Graduação em Computação" [Zorzo et al. [S.d.]]; como reportagens feitas por veículos de circulação nacional disponíveis online e sob forma impressa; os próprios catálogos nacionais de cursos desenvolvidos pelo Ministério da Educação [BRASIL. Ministério da Educação 2014, 2016]; e matérias em programas televisivos, não abundam materiais trazendo um guia de curso e carreira voltados para o público feminino, seja pela proposta de um design convidativo, seja por dar voz a mulheres. E, apesar da existência de podcasts feitos pelo e para o público feminino, como o 
"Mulheres de Produto"1 [Erica Castro et al. 2018] e "PodProgramar"2 [Jessi Zanelato and Ana Eliza 2016], eles não têm um direcionamento tão voltado a uma apresentação dos cursos com um olhar de destaque ao público feminino, como é a proposta do projeto aqui apresentado.

O protagonismo feminino pode inicialmente não parecer tão decisivo, mas os estudos de [Macedo et al. 2018] apontaram como fator positivo de influência na escolha de cursos de graduação na área das Exatas por parte de mulheres "Presença de um(a) professor(a) de Exatas influente durante o Ensino Médio" e "Presença de uma "pessoa modelo na mídia e/ou família”." [Macedo et al. 2018 n.p.] Assim, a proposta do projeto de extensão desenvolvido foi a criação de materiais que tivessem um apelo especial ao público composto por mulheres, seja pela apresentação visual, seja por dar voz e apresentar a perspectiva feminina de quem trabalha na área. Pensando em abranger um público variado e inclusivo, optou-se por produzir tanto material de cunho visual fôlderes -, quanto materiais em áudio - podcasts disponibilizados em plataformas variadas online -, assim, poder-se-ia contemplar também pessoas cegas ou com baixa visão.

\section{Materiais e método}

O projeto teve em sua totalidade a duração de dois meses e contou com fomento interno do câmpus onde se desenvolveu. As bolsistas eram discentes do curso Superior de Tecnologia de Análise e Desenvolvimento de Sistemas e foram escolhidas por entender quais são as dúvidas e os anseios de mulheres que estão prestes a ingressar ou já ingressaram em curso ligado à Tecnologia da Informação (TI). Elas atuaram em todas as etapas do projeto, desde a pré-produção até a pós-produção, as quais serão descritas nos parágrafos a seguir.

A primeira etapa do projeto consistiu em escolher quais seriam os materiais produzidos para divulgação dos cursos da área de TI. Pensando-se na realidade do câmpus onde o projeto se desenvolve, que recebe alunos cegos e surdos, pensou-se em diversificar os materiais, abrangendo as esferas orais e escritas, optando-se pela criação do gênero discursivo podcast e fôlder. A ideia inicial é que os fôlderes e os podcasts trouxessem informações básicas sobre os mesmos cursos, com algumas variações devido às características e espaço disponível para cada gênero discursivo, mas que se complementassem entre si.

Assim, a escolha pela produção do podcast se deu por esse gênero discursivo estar ganhando cada vez mais espaço na vida das pessoas [Villarta-Neder and Ferreira 2020], inclusive para estreitar as relações de ensino-aprendizagem. Ele "pode ser construído a partir de textos, vídeos ou áudios, sendo, no entanto, predominante a postagem de áudios." [Villarta-Neder and Ferreira 2020 p. 37]. Os autores ainda destacam como característica do podcast em áudio estar hospedado em um feed de uma página ou ambiente digital; e se constituir como prática social por envolver uma fidelização do ouvinte. [Villarta-Neder and Ferreira 2020]

Já no que diz respeito à produção do fôlder, pensou-se nesse gênero “impresso de pequeno porte, constituído de uma só folha de papel com uma ou mais dobras sanfonadas. De conteúdo informativo [...]" [Costa 2009 p. 114]. Embora para a comunidade surda a língua portuguesa não seja materna, houve certa limitação na produção do material impresso em língua brasileira de sinais, já que o projeto foi de

1 https://open.spotify.com/show/1rfUWxL2Ia7kA343ClLya1

2 https://podprogramar.com.br/ 
curta duração e o único intérprete de Libras do câmpus estar com demanda de trabalho muito grande para poder ajudar na tradução. A mesma limitação refere-se ao uso do braile, que requer profissionais qualificados, materiais e equipamentos adequados.

O próximo passo foi a pré-produção, que consistiu em fazer algumas pesquisas prévias para levantar as possibilidades de cursos de computação e elencar informações interessantes a serem incluídas no material pensando nas necessidades do público-alvo. Foi elaborado um template de roteiro para a gravação dos episódios do podcast. $\mathrm{O}$ roteiro contava com uma apresentação inicial do projeto e da bolsista extensionista e uma breve introdução sobre cada curso. Também foram incluídas perguntas para as entrevistadas e um fechamento para o episódio.

Em seguida, foi feita uma chamada para a lista de e-mails do Meninas Digitais da SBC explicando o projeto e convidando as integrantes que tivessem interesse de participar para serem entrevistadas para composição dos episódios do podcast. Cada entrevistada deveria gravar os áudios em seu próprio telefone celular e carregá-los em uma pasta personalizada com seu nome compartilhada pelo projeto no Google Drive; ou então, enviá-lo para um grupo de Whatsapp específico para esse fim. As instruções dadas para as gravações incluíam o pedido de que elas dessem respostas o mais completas possíveis e que fossem feitos em arquivos diferentes, para facilitar a parte de pós-produção (edição, colagem com a parte da entrevistadora e finalização).

Foi com base nas entrevistas com as seis mulheres que se procedeu à pósprodução dos episódios, composta (i) pela pesquisa de informações complementares sobre o curso para inserção no bloco de apresentação do episódio; (ii) edição dos áudios recebidos; (iii) montagem dos episódios; (iv) finalização; (iv) e disponibilização online. Tanto para a etapa de pós-produção, quanto para a produção (gravação da apresentação e finalização do episódio pela entrevistadora; e disponibilização online), foi utilizada a plataforma Anchor.

Os dois fôlderes produzidos foram feitos a partir da ferramenta de design online Canva na versão "For Education". Em cada fôlder foram incluídas informações sobre: (i) a diferença entre as diferentes habilitações em cursos superiores - bacharelado, licenciatura e tecnólogo; (ii) nome do curso e a(s) habilitação(ões) disponíveis; (iii) tempo de duração; (iv) características do mercado de trabalho; (v) média salarial; (vi) expectativa salarial; e (vii) breve descrição das atribuições da profissional. Cada fôlder abrangeu quatro cursos distintos e foi dada prioridade aos cursos abordados no podcast. Contudo, como sobrou espaço, foram adicionados quatro cursos não contemplados inicialmente no podcast.

\section{Resultados e Discussão}

Como resultado do projeto, foram produzidos quatro episódios do podcast, contemplando cada um curso distinto: Ciência da Computação, Licenciatura em Computação, Engenharia de Computação e Sistemas de Informação. Os episódios foram disponibilizados em todas as plataformas ofertadas pela ferramenta de criação Anchor, podendo ser encontrado nas plataformas Spotify ${ }^{3}$, Google podcasts ${ }^{4}$, RadioPublic ${ }^{5}$,

3 Disponível em: https://www.spotify.com/br/elasdigitais

4 Disponível em: https://podcasts.google.com/podcasts? feed=aHR0cHM6Ly9hbmNob3IuZm0vcy8zY2RmZDFkMC9wb2RjYXN0L3Jzcw==

5 Disponível em: https://radiopublic.com/podcast-carreiras-na-ti-elas-dig-Wlbp3L 
Breaker ${ }^{6}$. Como mencionado na seção 2, apesar de ser um gênero preponderantemente oral, foi produzida também uma pequena arte visual para todos os episódios do podcast e quatro artes, uma para cada episódio, em que apenas o nome do curso é modificado.

A duração de cada episódio varia bastante: o menor tem seis minutos de duração e o maior tem 23 minutos. Essa variação se deve ao número de entrevistadas por episódio (o maior episódio teve duas entrevistadas) e também aos áudios enviados pelas entrevistadas, já que não foi estipulado tempo mínimo ou máximo para cada resposta. Foi acrescentada também uma pequena descrição sobre cada episódio.

Os maiores desafios de produção do podcast consistiram em depender de ajuda externa, já que se necessitou aguardar pelo envio das respostas gravadas; e o escasso tempo para produção e pós-produção dos episódios. Poder-se-ia ter optado pela produção do podcast sem a participação de entrevistadas, pensando-se em celeridade no processo e um número maior de episódios. Porém, considerou-se que os resultados seriam mais ricos, já que havia pluralidade de experiências e percepções, e as profissionais da área se sentiriam mais valorizadas se a elas fosse concedido um lugar de fala em uma área geralmente ocupada por homens.

Foram produzidos também dois fôlderes apresentando quatro cursos cada um. Esses fôlderes, além dos cursos abordados no podcast, abordaram ainda Redes de Computadores, Engenharia Elétrica, Design de Games, Análise e Desenvolvimento de Sistemas, Desenvolvimento Web. Foi possível abordar um número maior de cursos porque a produção de material visual requer menos tempo. Esses materiais tiveram uma abordagem um pouco diferente da adotada no podcast pela natureza do gênero discursivo ser predominantemente escrito. Assim, primou-se por inserir informações mais pontuais e de leitura rápida e fácil, apoiados por recursos visuais, e trazendo informações complementares.

O design foi desenvolvido pelas alunas extensionistas com base na identidade visual já desenvolvida para as postagens do projeto Elas Digitais nas redes sociais. Deuse preferência pelo uso de cores variadas e figuras relacionadas às carreiras e de meninas e mulheres para chamar atenção em especial do público feminino. O material ficará disponível para download na aba "materiais disponíveis" no site do projeto7. A ideia é que ele seja divulgado amplamente através de vários meios.

Além de todo o material efetivamente finalizado, o projeto conseguiu criar subsídios para a finalização de novos episódios do podcast e fôlderes no mesmo modelo, já que o template de roteiro, os áudios de apresentação e finalização dos episódios, a vinheta, a arte visual do podcast $e$ a arte visual dos fôlderes podem ser aproveitados novamente para se produzir novos materiais do mesmo gênero discursivo.

Houve, segundo os dados fornecidos pela própria plataforma Anchor, 188 visualizações dos quatro episódios até o final de março de 2021. Dessas, $71 \%$ do público foi constituído por homens; $25 \%$ por mulheres; e $4 \%$ dos ouvintes não especificou o gênero. Assim, apesar de um direcionamento maior ao público feminino, o número de espectadores masculinos ainda foi maior, reforçando a necessidade de cada vez mais visibilidade de mulheres que atuem na Computação. A faixa etária dos ouvintes foi bem esparsa, predominando aqueles entre 18 a 22 anos (32\%), seguidos por indivíduos entre e 23 a 27 anos (26\%) e por pessoas entre 35 a 44 anos (21\%). Já em relação aos fôlderes, eles foram disponibilizados pelo perfil do projeto nas redes sociais

6 Disponível em: https://www.breaker.audio/podcast-carreiras-na-ti-elas-digitais

7 https://elasdigitais.wordpress.com 
- obtendo 16 curtidas -, pelo jornalismo institucional, pelo site do projeto, além de internamente pelos professores do câmpus. A menor repercussão dos fôlderes possivelmente se deu pelo fato de ser mídia impressa, o que no presente momento pode ser menos atrativo que lives, podcasts, vídeos. Futuramente, pós-pandemia, esse recurso poderá ser melhor aproveitado para distribuição em eventos presenciais.

\section{Considerações finais}

O projeto se provou ter custos baixos, tendo como principal necessidade orçamentária a contratação de duas bolsistas. O fato de as bolsistas serem discentes de um curso superior na área de TI foi fundamental para que os materiais produzidos contemplassem perguntas reais de meninas e mulheres, já que as perguntas e informações contempladas no material foram elaboradas com participação delas.

Uma dificuldade encontrada durante a execução foi o equilíbrio entre o trabalho e o estudo remoto; e o final do semestre letivo de 2020. Apesar dos contratempos, considera-se que os resultados foram além dos esperados inicialmente pela equipe do projeto.

Espera-se que seja possível atrair mais meninas e mulheres para os cursos da área da TI. O desejo é que esses resultados sejam perceptíveis nos números da instituição de ingresso e conclusão do público feminino ano após ano.

\section{References}

BRASIL. Ministério da Educação (2014). Catálogo Nacional de Cursos Técnicos. . Ministérios da Educação. http://portal.mec.gov.br/index.php? option=com_docman\&view=download\&alias=16705-res1-2014-cne-ceb-

05122014\&category_slug=dezembro-2014-pdf\&Itemid=30192, [accessed on Feb $12]$.

BRASIL. Ministério da Educação (2016). Catálogo Nacional de Cursos Superiores em Tecnologia. . Ministérios da Educação. http://portal.mec.gov.br/index.php? option=com_docman\&view $=$ download\&alias=98211-cncst-2016a\&category_slug=outubro-2018-pdf-1\&Itemid=30192, [accessed on Feb 12].

Costa, S. R. (2009). Dicionário de Gêneros Textuais. 2. ed. Belo Horizonte: Autêntica.

Erica Castro, Maria Oliveira, and Lenka Rejfirrová (2020 2018). Mulheres de Produto. https://open.spotify.com/show/1rfUWxL2Ia7kA343ClLya1, [accessed on Feb 15].

Jessi Zanelato and Ana Eliza (2020 2016). PodProgramar | Porque nós podemos! https://podprogramar.com.br/, [accessed on Feb 15].

Macedo, M. M. G., Mattos, A. B., Vasconcelos, M., Martinazzo, A. and Lopes, R. (9 aug 2018). Identificando Influências na Escolha de uma Graduação emExatas: um Estudo Qualitativo e Comparativo de Gênero. In Anais do Women in Information Technology (WIT). . Sociedade Brasileira de Computação - SBC. https://sol.sbc.org.br/index.php/wit/article/view/3371/3333, [accessed on Feb 12].

Villarta-Neder, M. A. and Ferreira, H. M. (4 aug 2020). O PODCAST COMO GÊNERO DISCURSIVO: ORALIDADE E MULTISSEMIOSE AQUÉM E ALÉM DA SALA DE AULA. Letras, p. 35-56.

Zorzo, A. F., Nunes, D., Steinmacher, I., et al. ([S.d.]). Referenciais de Formação para os Cursos de Graduação em Computação 2017. 